\title{
Rudimentary horn pregnancy: a rare entity
}

\section{Sujamol Jacob*, Lalithambica Karunakaran, Neena Devasia}

Department of Obstetrics and Gynecology, TDMC, Government Medical College, Alappuzha, Kerala, India

Received: 09 January 2020

Revised: 05 February 2020

Accepted: 11 February 2020

\section{*Correspondence:}

Dr. Sujamol Jacob,

E-mail: minujohn63@gmail.com

Copyright: () the author(s), publisher and licensee Medip Academy. This is an open-access article distributed under the terms of the Creative Commons Attribution Non-Commercial License, which permits unrestricted non-commercial use, distribution, and reproduction in any medium, provided the original work is properly cited.

\begin{abstract}
Unicornuate uterus is the type 2 variety of mullerian duct anomaly resulting in unilateral agenesis or hypoplasia. The hypoplastic (Rudimentary) horn can be functioning or non-functioning and communicating or noncommunicating with the main uterine cavity. Pregnancy in the rudimentary horn is an extremely rare entity. It is often missed at ultrasound in the early trimester, presenting later with massive hemoperitoneum and shock from rupture of the horn. A "high index of suspicion" is essential to derive at the correct diagnosis. Hence reporting this rare case for emphasizing the importance in early diagnosis and prompt management.
\end{abstract}

Keywords: Excision, Hemoperitoneum, Methotrexate, Pregnancy, Rupture, Rudimentary horn, Unicornuate uterus

\section{INTRODUCTION}

Rudimentary horn is an anatomic variant of unicornuate uterus which is a Mullerian duct anomaly resulting from incomplete fusion of the ducts. Such horn may or may not be communicating with the main uterus and may have a functional endometrium. The incidence of mullerian duct malformations in the general population is around $4 \%$ and that of unicornuate uterus is only about $0.4 \% .^{1}$ Pregnancy in the rudimentary horn is an extremely rare phenomenon, occurring in approximately 1 in 76,000 to 1 in $1,40,000$ pregnancies. $^{2}$

Pregnancy in a noncommunicating horn occurs by trans peritoneal migration of spermatozoa or the fertilized ovum.

We report one such rudimentary horn pregnancy diagnosed at 19 weeks gestation, which was missed on routine early pregnancy ultrasound scan and referred to the tertiary care Medical College Hospital of Alappuzha district, Kerala, India, following impending rupture of the rudimentary horn and hemoperitoneum.

\section{CASE REPORT}

A 24 years old G2P1L1 presented at 19 weeks gestation with abdominal discomfort and shoulder pain of one day duration, for which she was referred from a peripheral health center to Medical College, Hospital of Alappuzha district, Kerala, as a case of pregnancy with hemoperitoneum of unknown etiology.

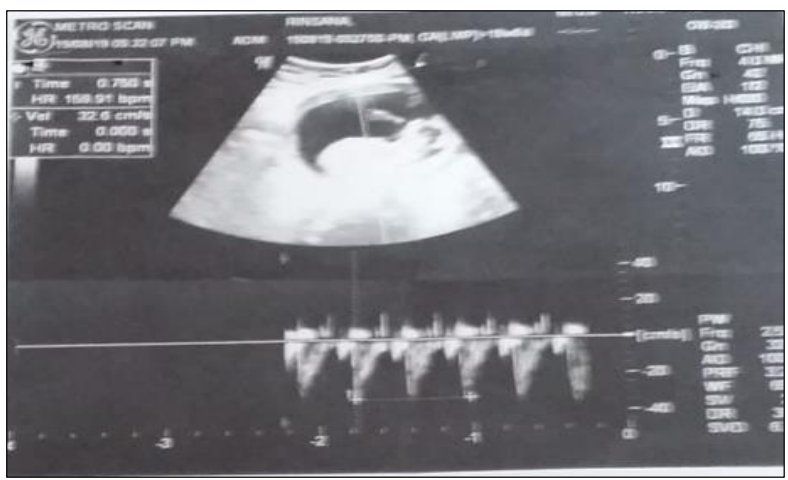

Figure 1: Ultrasound picture reported as a single live intra uterine gestation of 12 weeks. 
The lady had a previous uneventful vaginal delivery of a $1.9 \mathrm{~kg}$ baby 4 years back. There was no history of miscarriage, Medical termination of pregnancy, caesarean section or myomectomy to suspect a uterine rupture. She had regular antenatal checkups from a peripheral hospital. Dating ultrasound done at 13 weeks gestation showed a single live intrauterine pregnancy of 12 weeks 1 day (Figure 1). Cervical length was recorded as $3.7 \mathrm{~cm}$ and internal os closed. There was no uterine or adnexal mass noted and no free fluid in pouch of Douglas.

Antenatal check-up continued in the same hospital and repeat ultrasound scan done at 18 weeks also reported a single live intrauterine gestation with placenta attached to anterior wall upper segment. Moderate free fluid was present in pouch of Douglas but was not considered significant as patient was asymptomatic.

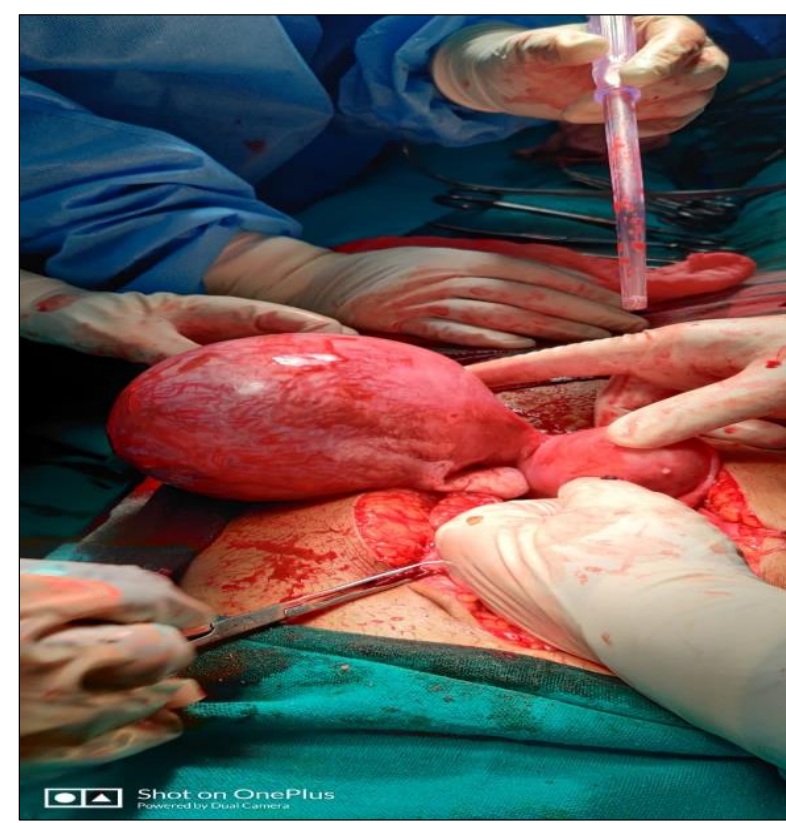

Figure 2: Intra operative finding showing enlarged pregnant Rudimentary horn with bleeding vessels and attached left ovary and with normal sized uterus on right side.

Six days after the scan the patient presented with symptoms of abdominal discomfort and distension, when a repeat emergency ultrasound revealed significant free fluid in peritoneal cavity, suspicious of extra uterine pregnancy with rupture. Hence referred to the center.

At admission, patient was having pallor, tachycardia of 120 beats/minute, BP-100/70. She was restless with abdominal pain and shoulder pain and unable to lie supine. Abdominal examination revealed a 20 weeks palpable uterus and clinical evidence of free fluid.

An emergency USG revealed moderate free fluid with low level internal echoes suggestive of hemo peritoneum and a gravid uterus with single live fetus. In view of free fluid, paracentesis was done which revealed dark altered fluid blood. Hence the patient was taken up for emergency laparotomy. Her pre-operative hemoglobin was $8 \mathrm{gm} \%$.

At laparotomy, peritoneal cavity contained $1000 \mathrm{ml}$ fluid blood and 300 gms clots. Uterus was unicornuate and normal size and had an enlarged left rudimentary horn of $10 \times 10 \mathrm{~cm}$ size attached to the main uterus by only a band of fibro muscular tissue (Figure 2).

The horn was in a state of impending rupture with multiple dilated vessels with fresh bleeding which was the cause for hemoperitoneum. Left tube and ovary was attached to the rudimentary horn. Excision of the pregnancy horn and left salpingectomy was done (Figure 3). Hemostasis attained.

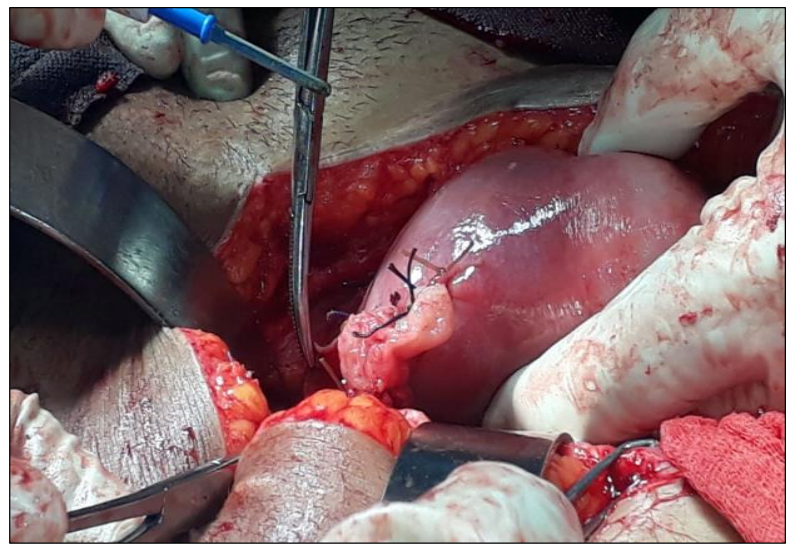

Figure 3: Excision of horn with left adnexectomy done.

Abdomen lavaged and closed in layers after keeping drain. Cut open section of the resected horn showed the fetus inside (Figure 4). Two units PRC and 2 FFP transfused intra operatively. Post-operative period was uneventful and discharged on $8^{\text {th }}$ post-operative day.

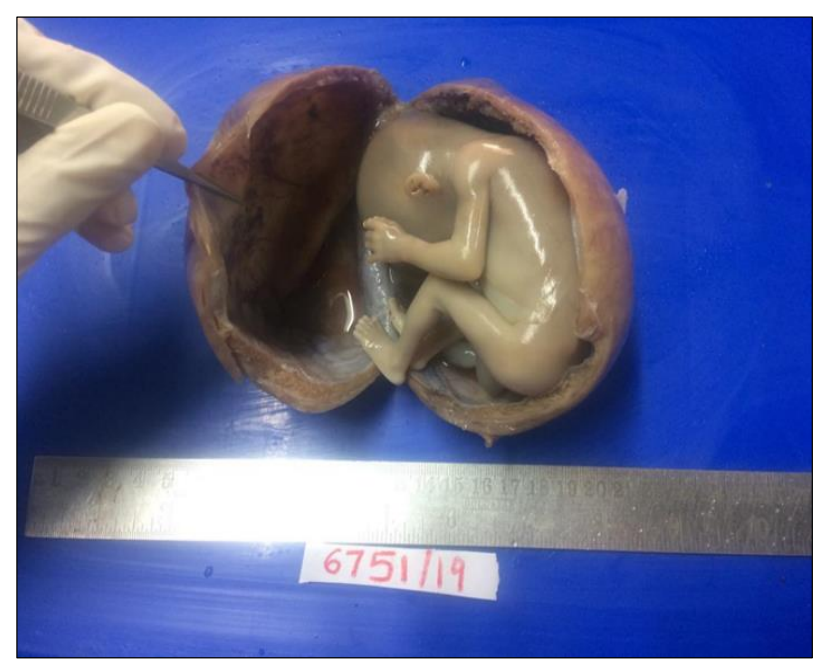

Figure 4: Resected rudimentary horn cut open showing fetus inside. 


\section{DISCUSSION}

Mullerian anomalies were first classified by Buttram and Gibbons in 1979 and later revised by American society of Reproductive Medicine in 1988 (Figure 5).

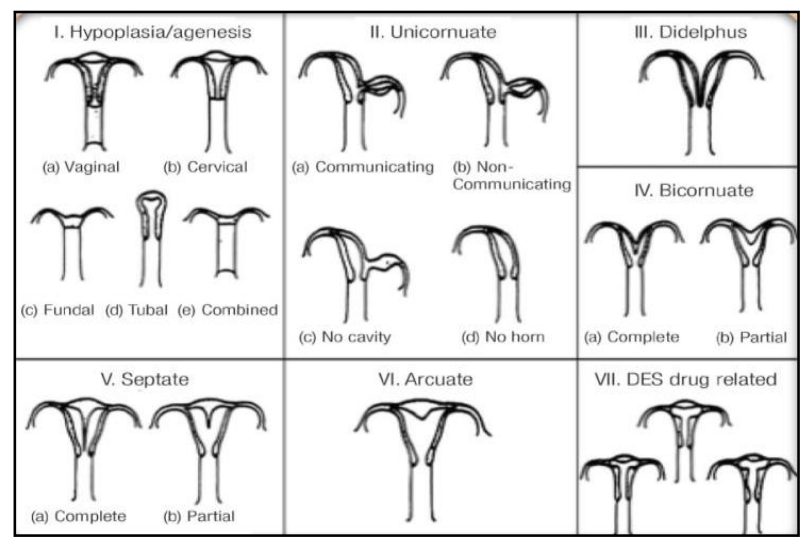
Figure 5: ASRM classification of uterine
mullerian anomalies.

Unicornuate uterus is the type 2 variety where there is incomplete fusion of the mullerian duct resulting in unilateral agenesis or hypoplasia. This is further subclassified as functioning communicating (IIa) or functioning non-communicating horn (IIb), nonfunctioning horn (IIc) or no horn at all (IId). ${ }^{1} 70-80 \%$ of rudimentary horn are non-communicating with the main uterine cavity. ${ }^{2}$

Unicornuate uterus with functioning noncommunicating rudimentary horn can become symptomatic at an early age presenting as collection of blood within the horn or as endometriosis in the adolescent population. Later in reproductive age group pregnancy in unicornuate uterus can present as recurrent miscarriage, preterm delivery and other pregnancy complications like intrauterine growth restriction, breech presentation, placenta previa, placental abruption and as pregnancy in rudimentary horn with the dreaded life-threatening complication of rupture during pregnancy.

Pregnancy in a rudimentary horn is extremely rare and the diagnosis in a woman with prior normal pregnancy and vaginal delivery is often difficult. It can be missed on routine ultrasound scans as in this case report. It needs a high index of suspicion at ultrasound evaluation of first trimester of pregnancy to derive at a correct diagnosis. It usually terminates in rupture during the first or second trimester of pregnancy and diagnosed after rupture with the patient presenting with massive hemoperitoneum and shock. $70-80 \%$ of rupture occurs by the end of second trimester, although the timing of rupture can vary from $5^{\text {th }}$ to $34^{\text {th }}$ week of gestation depending on the strength of the musculature of the horn. ${ }^{3}$ As the uterine musculature is thicker and more vascular than the fallopian tube, the bleeding is more severe and often can be life threatening. ${ }^{4}$
It can also be misdiagnosed as intrauterine pregnancy with fetal demise by ultrasound where a termination of pregnancy with misoprostol was attempted but fails or subsequently develops rupture with hemoperitoneum and shock. $^{5}$

The first case of rudimentary horn pregnancy rupture was reported by Mauriceau and Vassal in $1669 .{ }^{6}$ Kadan and Romano described rudimentary horn rupture as a significant threat to pregnancy and a life threatening condition. ${ }^{7}$ Maternal mortality rate before 1900 was reported to be almost $50 \%$ but since 1960's although rupture still occurs, no case of maternal mortality has been reported. ${ }^{8}$ But morbidity can be high in view of massive blood loss and surgery in a collapsed patient.

Early diagnosis of the condition is essential but can be challenging. A high index of suspicion in the early first trimester scan helps in correct diagnosis. Ultrasound, hysterosalpingogram, hysteroscopy, laparoscopy and MRI are the various diagnostic tools in the non-pregnant state. Ultra sound and MRI are the options for diagnosis in pregnancy. ${ }^{9}$ But the sensitivity of ultrasound is only $30 \%$ and decreases further as pregnancy advances. ${ }^{10} \mathrm{It}$ can also be missed in inexperienced hands. Intra uterine pregnancy, tubal pregnancy cornual pregnancy and abdominal pregnancy are the common misdiagnosis made. 3-dimensional ultrasound imaging can improve the diagnostic accuracy. Inconclusive USG reports has to be subjected to confirmation by MRI. There has been reports of first trimester pre rupture diagnosis of rudimentary horn pregnancy. Fedele et al have found USG to be useful in diagnosis. ${ }^{11}$

The $20^{\text {th }}$ century worldwide study of 588 cases of rudimentary horn pregnancy during the period 1900-1999 conducted by manual and computerized standard reference tracing showed that $85 \%$ of pregnancies occurred in non-communicating horns. $50 \%$ of pregnant horns ruptured, with $80 \%$ of these events occurring before the third trimester. Maternal mortality decreased from $23 \%$ to $6 \%$ during the first half of the century to < $0.5 \%$ in the later half. ${ }^{12}$

Tsafrir et al, reported 2 cases of rudimentary horn pregnancy confirmed by MRI and they outlined a set of criteria for the diagnosis of rudimentary horn pregnancy. ${ }^{13}$

They are

- A pseudo pattern of asymmetrical bicornuate uterus

- Absent visual continuity of tissue surrounding the gestation sac and the uterine cervix

- Presence of myometrial tissue surrounding the gestational sac.

Still many of the cases can remain undiagnosed until it ruptures and present as emergency. Additionally, hypervascularization typical of placenta accreta may 
suggest diagnosis of rudimentary horn pregnancy. This feature can be diagnosed by color flow Doppler and power Doppler sonography. ${ }^{14}$

Definitive management of rudimentary horn is surgical excision of the horn with ipsilateral fallopian tube. ${ }^{15}$ Removal prior to pregnancy in order to prevent complications is ideally advised if diagnosis is made in the non-pregnant state. However, those women who refuse to do so should be adequately counseled regarding this potential complication and if pregnancy occurs in the rudimentary horn, first trimester excision should be advocated.

For those diagnosed in early pregnancy, immediate surgery is recommended in the unruptured state. However very rarely conservative management until viability is achieved has been reported in a few selected cases when the condition was diagnosed late in pregnancy and if emergency surgery can be performed at any time and the patient well informed. A case report of pregnancy in rudimentary horn diagnosed in third trimester resulting in live birth after cesarean section has also been reported. ${ }^{16}$

Early diagnosis before rupture ideally can be managed laparoscopically. Dicker et al removed a small rudimentary horn $5 \times 5 \mathrm{~cm}$ in unruptured state laparoscopically. ${ }^{17}$ Yahata et al used endoscopic staplers to tranect the fibrous band connecting the rudimentary horn to the uterus18. The first case of laparoscopic resection was reported in 1996. Although traditionally this surgery was done by laparotomy, laparoscopy is now a better and attractive option because of early recovery. However, if pregnancy is well advanced or a broad area of attachment to the main uterus is suggested by imaging, laparotomy may be a better option. But in majority of cases the rudimentary horn is attached to the main uterus by only a fibro muscular band which can be resected laparoscopically in a hemodynamically stable patient.

Ruptured rudimentary horn pregnancy with massive hemo peritoneum and shock is an indication for immediate laparotomy, excision of the horn and blood transfusion to save the patient.

Medical management with methotrexate followed by elective laparoscopic resection is also reported. ${ }^{19}$ Edelman et al reported a case diagnosed at an early gestational week and treated successfully with methotrexate administration. ${ }^{20}$ Therefore in asymptomatic patients with an early gestation located in noncommunicating rudimentary horn, methotrexate may provide another treatment or act as a useful adjunct to surgical intervention.

\section{CONCLUSION}

Despite advances in ultrasound and other diagnostic modalities, prenatal and early antenatal diagnosis of rudimentary horn pregnancy still remains elusive. As in this case, even in the phase of impending rupture with significant hemoperitoneum, diagnosis of rudimentary horn pregnancy was missed. This shows the need for high index of suspicion of this relatively rare life-threatening complication in every patient undergoing an early first trimester scan. Proper diagnosis and early referral from peripheral hospitals is needed to reduce the morbidity and mortality associated with rudimentary horn pregnancy. Precious time may be lost due to delay in diagnosis or misdiagnosis and the general condition of the patient may worsen as in this case. Timely resuscitation, immediate surgery and adequate blood transfusion are the essential steps in the management needed to save the patient with ruptured rudimentary horn pregnancy.

This case report highlighted the need for increased awareness and high index of suspicion of this rare but life-threatening complication of pregnancy. When such a rudimentary horn pregnancy is diagnosed, the excision of the horn with ipsilateral salpingectomy is the recommended surgical treatment for the best prognosis.

\section{Funding: No funding sources \\ Conflict of interest: None declared \\ Ethical approval: Not required}

\section{REFERENCES}

1. Acién P, Acién MI. The history of female genital tract malformation classifications and proposal of an updated system. Hum Reprod Update. 2011;17:693705.

2. Okonta PI, Abedi H, Ajuyah C, Omo-Aghoja L. Pregnancy in a noncommunicating rudimentary horn of a unicornuate uterus: a case report. Cases J. 2009;2:6624.

3. O'leary JL, O'leary JA. Rudimentary horn pregnancy. Obstet Gynecol. 1963;22:371-4.

4. Chowdhury S, Chowdhury T, Azim E. Pregnancy in a non-communicating rudimentary horn of uterus: a clinical case report. Bangladesh Med J. 2010;39(1):47-8.

5. Samuels TA, Awonuga A. Second-trimester rudimentary uterine horn pregnancy: rupture after labor induction with misoprostol. Obstet Gynecol. 2005;106(5):1160-2.

6. Mauriceau F. Traite des maladaies des femmes grosses, Compaigne des libraries, Paris, France; 1721:1.

7. Kadan Y, Romano S. Rudimentary horn pregnancy diagnosed by ultrasound and treated by laparoscopya case report and review of the literature. J Mini Inva Gynecol. 2008;15(5):527-30.

8. Nahum G. Rudimentary uterine horn pregnancy: the $20^{\text {th }}$-century worldwide experience of 588 cases. J Reprod Med. 2002;47(2):151-63.

9. Lawhon BP, Wax JR, Dufort RT. Rudimentary uterine horn pregnancy diagnosed with magnetic resonance imaging. Obstet Gynecol. 1998;91(5):869. 
10. Jayasinghe Y, Rane A, Stalewski H, Grover S. The presentation and early diagnosis of the rudimentary uterine horn. Obstet Gynecol. 2005;105(6):1456-67.

11. Fedele L, Dorta M, Vercellini P, Brioschi D, Candiani BG. Ultrasound in the diagnosis of subclasses of unicornuate uterus. Obstet Gynecol. 1998;71(2):274-7.

12. Nahum G. Rudimentary uterine horn pregnancy: the $20^{\text {th }}$-century worldwide experience of 588 cases. J Reprod Med. 2002;47(2):151-63.

13. Tsafrir A, Rojansky N, Sela HY, Gomori JM, Nadjari M. Rudimentary horn pregnancy: firsttrimester prerupture sonographic diagnosis and confirmation by magnetic resonance imaging. J Ultra Med. 2005;24(2):219-23.

14. Henriet E, Roman H, Zanati J, Lebreton B, Sabourin JC, Loic M. Pregnant noncommunicating rudimentary uterine horn with placenta percreta. JSLS. 2008;12:101-3.

15. Buntugu K, Ntumy $M$, Ameh E, Obed S. Rudimentary horn pregnancy: pre-rupture diagnosis and management. Ghana Med J. 2008;42:92-4.

16. Shin JW, Kim HJ. Case of live birth in a noncommunicating rudimentary horn pregnancy. J Obstet Gynaecol Res. 2005;31(4):329-31.
17. Dicker D, Nitke S, Shoenfeld A, Fish B, Meizner I, Ben-Rafael Z. Laparoscopic management of rudimentary horn pregnancy. Human Repro. 1998;13(9):2643-4.

18. Yahata T, Kurabayashi $\mathrm{T}$, Ueda H, Kodama S, Chihara T, Tanaka K. Laparoscopic management of rudimentary horn pregnancy: a case report. J Reprod Med Obstet Gynecol. 1998;43(3):223-6.

19. Sevtap HK, Aral AM, Sertac B. An early diagnosis and successful local medical treatment of a rudimentary uterine horn pregnancy: a case report. Arch Gynecol Obstet, 2007;275(4):297-8.

20. Edelman AB, Jensen JT, Lee DM, Nichols MD. Successful medical abortion of a pregnancy within a noncommunicating rudimentary uterine horn. Am J Obstet Gynecol. 2003;189(3):886-7.

Cite this article as: Jacob S, Karunakaran L, Devasia N. Rudimentary horn pregnancy: a rare entity. Int J Reprod Contracept Obstet Gynecol 2020;9:1761-5. 